\title{
Sentidos da Saúde numa Perspectiva de Gênero: um Estudo com Homens da Cidade de Natal/RN ${ }^{1}$
}

\author{
Jáder Ferreira Leite \\ Magda Dimenstein \\ Universidade Federal do Rio Grande do Norte, RN, Brasil. Universidade Federal do Rio Grande do Norte, RN, Brasil. \\ Rafaele Paiva \\ Lúcia Carvalho \\ Universidade Federal do Rio Grande do Norte, RN, Brasil. Universidade Federal do Rio Grande do Norte, RN, Brasil. \\ Ana Karenina de Melo Arraes Amorim \\ Aparecida França \\ Universidade Federal do Rio Grande do Norte, RN, Brasil. \\ Universidade Potiguar, RN, Brasil.
}

Resumo: $\mathrm{O}$ presente trabalho objetivou investigar os sentidos atribuídos à saúde por homens da cidade de Natal/RN, em dois contextos: uma Unidade Básica de Saúde (UBS) de um bairro de classe média e uma Unidade de Saúde da Família (USF) de um bairro popular. Metodologicamente, realizamos entrevistas semiestruturadas junto a 24 homens, sendo 12 de cada serviço, com faixa etária de 25 a 59 anos, abordados nas unidades de saúde de cada bairro. A análise dos dados deu-se a partir da perspectiva de Spink (2000), e Spinke Frezza (2000) e Spinke Medrado (2000), no tocante às práticas discursivas e os estudos de gênero. Os dados encontrados acompanham a tendência de estudos já realizados no campo, especialmente ao identificar como as posições sociais de gênero conformam os sentidos que os homens investigados construíram em relação à saúde, atribuindo a esta a importância de proporcionar as condições de exercício de uma masculinidade voltada para o provimento do lar e da família. Houve diferença acerca dos sentidos sobre a resolução de problemas de saúde no tocante aos serviços investigados: a maioria do grupo da UBS apontou para pouca resolutividade, gerando sentidos de ineficácia do serviço. Na USF, os sentidos apresentaram uma positividade em relação ao serviço, que julgamos ter relação com a natureza da Estratégia de Saúde da Família. Finalmente, identificamos como a busca pelos serviços de saúde no nível de atenção básica é limitada, fato que segue os estudos de que os homens buscam os serviços de saúde quando esta se encontra demandando atenção especializada. Concluímos que a PNAISH pode ter uma importante contribuição na medida em que se efetive como política de saúde, sensibilizando a toda a rede de atores e serviços envolvidos na busca por novos sentidos e práticas em torno da relação gênero-saúde.

Palavras-chave: Saúde do homem, Produção de sentidos, Relações de gênero.

\section{Health senses a gender perspective: a study of men in the city of Natal/RN}

\begin{abstract}
This work had the objective of investigating the senses attributed by men to health in the city of Natal/RN, in two different contexts: one in a Basic Health Unity from a middle class neighborhood, and another in a Family Heath Unity of a popular neighborhood. We conducted semi-structured interviews with 24 men, between 25 and 59 years old, 12 from each group. The data analysis for the discursive practices and for the gender studies was done using Spink's perspective ( 200 \& Frezza, 2000; Sink \& Medrado, 2000). The found data follow the tendency of other researches already done in this area, especially when it comes to identify how gender social positions create the senses that the interviewed men built about "health", attributing to it the importance of providing
\end{abstract}

1. Pesquisa realizada com apoio do CNPq, por meio do Edital Universal/2010. 
the conditions for a masculinity exercise oriented to supporting their families and homes. There was a difference concerning the senses of resolution of problems related to health when it comes to the investigated services: the majority of the Basic Health Unity pointed to a small solving, creating senses of ineffectiveness of the service. In the Family Health Unity, however, the senses present a bigger positivity concerning the services. We believe that is explained by the nature of the "Family Health Strategy". Finally, we identified that the search for health services in the basic levels is limited, a fact that follows a study showing that men look for health services only when they are demanding specialized care. We conclude that the PNAISH could be an important contribution if turned into a health policy, sensitizing the entire network of actors and services involved in the search for new meanings and practices around the gender-health relationship.

Keywords: Men health, Senses production, Gender relations.

\title{
La salud detecta una perspectiva de género: un estudio de hombres en la ciudad de Natal/RN
}

\begin{abstract}
Resumen: El presente trabajo tiene como objetivo investigar los sentidos atribuidos a la salud por hombres de la ciudad de Natal/RN, en dos contextos: una Unidad Básica de Salud (UBS) de un barrio de clase media y una Unidad de Salud de la Familia (USF) de un barrio popular. Metodológicamente, realizamos entrevistas semiestructuradas a 24 hombres, 12 de cada servicio, con edades entre 25 y 59 años, abordados en las unidades de salud de cada barrio. El análisis de los datos se realizó desde la perspectiva de Spink (2000 \& Frezza, 2000; Spink \& Medrado, 2000) en lo que se refiere a las prácticas discursivas y los estudios de género. Los datos encontrados acompañan la tendencia de los estudios ya realizados en el campo, especialmente al identificar cómo las posiciones sociales de género conforman los sentidos que los hombres investigados construyeron en relación a la salud, atribuyendo a esta la importancia de proporcionar las condiciones de ejercicio de una masculinidad orientada hacia el proveimiento del hogar y de la familia. Hubo diferencia en los sentidos atribuidos a la resolución de problemas de salud en lo que se refiere a los servicios investigados: la mayoría del grupo de la UBS señaló poca capacidad de resolución de problemas, generando sentido de ineficacia del servicio. En la USF, los sentidos presentaron positividad en relación a los servicios, que creemos que tienen relación con la naturaleza de la Estrategia de Salud de la Familia. Finalmente, constatamos que es limitada la búsqueda de servicios de salud en el nivel de la atención básica, hecho que concuerda con los estudios que constatan que los hombres buscan los servicios de salud cuando se encuentran demandando atención especializada. Llegamos a la conclusión de que el PNAISH puede hacer una contribución importante si se hace efectivo como política de salud, sensibilizando a toda la red de actores y servicios implicados en la búsqueda de nuevos significados y prácticas en torno a la relación salud-género.

Palabras clave: Salud del hombre, Producción de sentidos, Relaciones de género.
\end{abstract}

\section{Introdução}

O tema da saúde dos homens vem se tornando mais presente nas agendas dos organismos internacionais e de países da América Latina, fazendo com que essa população e suas questões de saúde ganhem visibilidade, fato até então muito presente nas políticas de saúde de mulheres, crianças e idosos.
Para Carrara, Russo e Faro (2009), tal visibilidade ainda aponta dificuldades em função de que a visão das ciências médicas sobre os homens, em geral, não o consideram como sujeitos generificados, ou seja, construídos historicamente a partir das relações de gênero, mas como representante humano generalizado. Os autores resgatam uma 
composição de processos que deram visibilidade à saúde do homem, tornando-o objeto de diversas disciplinas científicas, a saber: a) a forte atuação dos movimentos feministas e de Lésbicas, Gays, Bissexuais, Travestis e Transexuais (LGBTT), ao exercerem uma importante crítica ao modelo de dominação masculina; b) a considerável modificação sofrida nos modelos familiares (a descentralização da figura do homem como provedor da família e o surgimento de arranjos alternativos ao casal nuclear e heterossexual) que vem promovendo a ocupação de novos papéis para os homens nesse contexto e c) o fato de que atuais problemas de saúde tais como AIDS, a ausência de planejamento reprodutivo e a violência urbana crescente demandam uma efetiva participação dos homens na busca de sua resolução (Carrara et al., 2009).

No caso do Brasil, tais preocupações se converteram na implantação de uma política de saúde voltada para os homens, a partir da articulação de movimentos sociais, sociedades médicas e o Ministério da Saúde que, em agosto de 2009, lançou, através da Portaria MS no 1944/2009 (Brasil, 2009), a Política Nacional de Atenção Integral à Saúde do Homem no contexto do Sistema Único de Saúde (PNAISH).

A PNAISH vem preencher um vácuo no âmbito das políticas de saúde em face de já haver muitos programas voltados para determinados setores da população, tais como crianças e adolescentes, mulheres, pessoas idosas. No entanto, só a partir de então que se vem planejar e efetivar ações de saúde para a população masculina em diversos contextos (rurais e urbanos, gays, população carcerária, dentre outros). O documento norteador da PNAISH entende a saúde do homem como:

Um conjunto de ações de promoção, prevenção, assistência e recuperação da saúde, executado nos diferentes níveis de atenção. Deve-se priorizar a atenção básica, com foco na Estratégia de Saúde da Família, porta de entrada do sistema de saúde integral, hierarquizado e regionalizado (Brasil, 2008, p. 30).

Com base em tal compreensão, um elemento se destaca nessa política: o estímulo ao acesso dos homens a serviços de saúde no seu nível primário ou básico de atenção, no território onde vivem com suas famílias, haja vista que a busca por serviços costumam acontecer na atenção especializada, ou seja, quando os agravos à saúde já são consideráveis, havendo um retardamento da atenção e demandando maior complexidade de cuidados.

Dentre os principais agravos vividos pelos homens, especialmente na população adulta entre 25 e 59 anos que correspondem cerca de $20 \%$ da população brasileira (Brasil, 2008), destacam-se problemas cardiológicos, urológicos, de saúde mental, gastroenterológicos, pneumonias, além do fenômeno complexo da violência que incide fortemente sobre homens jovens e adolescentes.

Dados compilados pela Secretaria de Estado do Rio Grande do Norte (Rio Grande do Norte, 2012) ${ }^{2}$ destacam como alguns problemas de saúde apresentam maior incidência sobre a população masculina do Estado: para a AIDS, enquanto houve a notificação de 25 casos no ano de 2010 entre mulheres com faixa etária entre 25 a 49 anos, em relação aos homens de mesma faixa, as notificações chegaram em torno de 40 casos. O documento apresenta dados sobre o município de Natal, local da presente pesquisa, onde o tabagismo foi identificado em um percentual de $13,4 \%$ da população adulta, dos quais $18 \%$ eram do sexo masculino e $9,5 \%$ do sexo feminino. Em relação ao uso abusivo de álcool, houve uma taxa de $20,8 \%$ da população, dos quais $37,1 \%$ eram de homens com mais de 18 anos, enquanto para as mulheres era de $7,4 \%$.

A PNAISH aponta a necessidade de se debruçar sobre essas questões na medida em que a população masculina apresenta maior vulnerabilidade às doenças (especialmente as crônicas e graves) em relação às mulheres, baixa adesão aos serviços de saúde e necessidade da realização de prevenção primária em saúde (Ministério da Saúde, 2009).

Gomes, Nascimento e Araújo (2007) apontam que a procura por serviços de saúde, no âmbito da população masculina, dá-se principalmente por serviços emergenciais, como pronto-socorro e farmácias e, nesse último caso, configura-se para os homens como uma atenção semiprofissional de modo que, sem perda de tempo e necessidade de marcação de consulta, os homens tendem a solucionar seus

2. O documento aponta que os dados trabalhados podem sofrer alguma variação em função de que alguns casos não foram notificados. 
problemas de saúde. Desse modo, a presente investigação pretende situar tal problemática na perspectiva de gênero, por entender o forte atravessamento que ela tem no tratamento dessa questão.

Medrado e Lyra (2008) e Bento (2006) destacam que as teorizações de gênero só passaram a incluir os estudos sobre as masculinidades a partir das décadas de 1980 e 1990, quando mudaram a compreensão para a qual o gênero deveria ser tratado como uma categoria relacional. Tal perspectiva permitiu desconstruir a ideia "do homem universal, naturalmente viril, competitivo e violento" (Bento, 2006, p. 74).

Os primeiros estudos sobre gênero, segundo Bento (2006), pautaram-se basicamente em termos de explicar a subordinação feminina, gerando uma espécie de essencialização e vitimização da condição feminina e um apagamento do masculino. É somente a partir de uma reflexão que torna o gênero uma categoria relacional e analítica que masculino e feminino serão compreendidos como realidades construídas conjuntamente. Nesses termos, podemos compreender o conceito de gênero a partir de Scott (1995, p. 86), ao afirmar que: "(1) o gênero é um elemento constitutivo de relações sociais baseadas nas diferenças percebidas entre os sexos e (2) o gênero é uma forma primária de dar significado às relações de poder".

Há uma concepção em nossa cultura que naturaliza definições binárias dos modelos masculino e feminino situados em corpos, desejos e identidades. Medrado e Lyra (2008) recordam que esse aspecto relacional na constituição dos gêneros possibilita identificar jogos assimétricos e de poder no modo de configuração e subjetivação desses modelos, bem como permite repensar argumentações socialmente estabelecidas de culpabilização e vitimização de homens e mulheres. Punir os homens e vitimizar as mulheres. Esse binômio, de acordo com Granja e Medrado (2009), ganha enorme complexidade quando se reflete a questão da violência em que elementos de natureza cultural comparecem fortemente no delineamento das identidades de homens e de mulheres.

Além disso, ao se abordar numa perspectiva de gênero o campo da masculinidade, impele-nos a falar dela no plural, haja vista tratar-se de múltiplas possibilidades de assumir papéis em torno do que se possa chamar de universo masculino. Assim, concordamos com Medrado e Lyra (2008, p. 824), ao afirmarem que:
Não existe uma única masculinidade e que tampouco é possível falar em formas binárias que supõem a divisão entre formas hegemônicas e subordinadas. Tais formas baseiam-se nas posições de poder social dos homens, mas são assumidas de modo complexo por homens particulares, que também desenvolve relações diversas com outras masculinidades.

Outra importante reflexão nos estudos de gênero que se alia à desnaturalização das identidades de masculino e feminino diz respeito ao fato de que outros elementos entram em jogo na composição do que se percebe como atributo de homens e de mulheres que tornam a vivência dessas identidades problemáticas: trata-se de especificidades socioculturais e econômicas tais como: classe social, grupos indígenas, negros, gays, populações urbanas e rurais. Todos esses arranjos identitários acabam por relativizar os essencialismos construídos para conformar os papéis binários de gênero.

Se tomarmos o campo da saúde, percebemos como essa relativização pode se acentuar na medida em que processos de saúde-doença são vividos distintamente por essa diversidade de identidades. O fenômeno da saúde pode ser, desse modo, tomado como um analisador das formas de atualização das relações de gênero.

Nessa linha de argumentação é que a presente pesquisa teve por objetivo investigar os sentidos sobre saúde produzidos por homens da cidade do Natal/RN, em dois contextos socioeconômicos. A proposta de investigação a partir da produção de sentidos segue filiação à corrente do Construcionismo social tal com aparece no campo da Psicologia Social, segundo Spink e Frezza (2000) e Spink e Medrado (2000). A produção de sentidos é, desse modo, uma forma de conhecimento que se gera no cotidiano das interações sociais, por meio das práticas discursivas. Para Spink e Medrado (2000, p. 41):

O sentido é uma construção social, um empreendimento coletivo, mais precisamente interativo, por meio do qual as pessoas - na dinâmica das relações historicamente datadas e culturalmente localizadas - constroem os termos a partir dos quais compreendem e lidam com as situações e fenômenos a sua volta. 
Nessa abordagem, a linguagem se coloca como um importante articulador de produção de sentidos, contanto que seja tratada como linguagem em uso, quer dizer, uma prática social, com efeito performático, tomada em termos de suas condições de uso quanto de produção em determinado contexto social. Portanto, o elemento mediador da produção de sentidos são as práticas discursivas. Tais práticas são definidas como "linguagem em uso, isto é, as maneiras a partir das quais as pessoas produzem sentidos e se posicionam em relações sociais cotidianas" (Spink, \& Medrado, 2000, p. 45). Defendem os autores o caráter ativo dos sujeitos tanto na elaboração de conhecimentos, quanto no posicionamento em práticas sociais do cotidiano, destacando que, diferentemente do discurso que tende a revelar os conteúdos de regularidade linguística ou aqueles em que a linguagem se institucionalizou, por meio das práticas discursivas, é possível compreender o campo das ressignificações, das rupturas, portanto da heterogeneidade.

A possibilidade de situar as práticas discursivas em termos de uma regularidade ou de heterogeneidade aparece em Spink e Medrado (2000) numa abordagem temporal. Ou seja, estes autores situam o trabalho com o contexto discursivo de produção de conhecimentos em três tempos, a saber: "o tempo longo, que marca os conteúdos culturais, definidos ao longo da história da civilização; o tempo vivido, das linguagens sociais aprendidas pelos processos de socialização, e o tempo curto, marcado pelos processos dialógicos" (p. 51). O tempo curto, de que falam os autores, é o tempo da polissemia, ou seja, das produções discursivas em que os tempos anteriores se articulam e se atualizam com o tempo presente.

Assim, investigar os sentidos atribuídos à saúde por homens em duas realidades socioeconômicos na cidade do Natal/RN pode gerar uma reflexão que traga novos olhares para a desnaturalização dos lugares tradicionais de gênero, de modo a fazer falar a polissemia que reveste esse campo da vida social.

\section{Método}

Durante os anos de 2011 e 2012, foi realizada a etapa de campo através de visitas a uma Unidade Básica de Saúde (UBS) de um bairro de classe média e a uma Unidade de Saúde da Família de um bairro de classe popular da cidade do Natal/RN, com a finalidade de identificação de participantes para o presente estudo. Foram entrevistados 24 homens, sendo 12 de cada serviço de saúde, com idade compreendida entre 25 e 59 anos, abordados na sala de espera da unidade e que demonstraram interesse em participar da pesquisa por meio da assinatura de um termo de consentimento livre. A definição dessa faixa etária seguiu a mesma estabelecida pela PNAISH com vistas a valorizar tal recorte populacional. Outro critério para participação consistiu em que os indivíduos residissem no bairro em que está situada a unidade de saúde.

Um roteiro semiestruturado dividido em dois blocos de questões orientou a realização das entrevistas. O primeiro bloco versava sobre questões relacionadas à saúde e gênero, em que o entrevistado poderia discorrer os sentidos que ele atribuía à saúde e ao ser homem e as diferenças percebidas no cuidado entre homens e mulheres com sua saúde. $\mathrm{O}$ segundo bloco explorou os modos de cuidado do entrevistado com a sua saúde. Para o registro de áudio, utilizou-se um gravador mediante autorização prévia dos participantes.

A análise das entrevistas fundamentou-se na perspectiva das práticas discursivas, como sugerem Spink e Medrado (2000). Tal proposição privilegia o modo como as pessoas produzem conhecimento no âmbito do senso comum, a partir da multiplicidade de repertórios que as práticas discursivas apontam nas conversações (entendidas, neste caso, a partir do encontro entre pesquisador e participante).

Utilizou-se a perspectiva das práticas discursivas para análise das entrevistas que, no caso do primeiro bloco, foram elaborados mapas de associação de ideias (Spink, \& Lima, 2000) com a finalidade de acessar os repertórios utilizados bem como a dialogicidade presente na elaboração dos sentidos sobre os temas "saúde" e "homem". Como o segundo bloco das entrevistas mobilizava o entrevistado para experiências anteriores com a saúde, problemas vividos e atuais, as práticas discursivas foram sistematizadas por meio da elaboração de linhas narrativas (Spink, \& Lima, 2000).

\section{Resultados e discussão}

\section{Perfil dos participantes do estudo}

A pesquisa foi composta por dois grupos de doze homens, sendo o primeiro grupo (G1) residente em um bairro de classe média e o segundo (G2), em um bairro de classe popular da cidade. No primeiro caso (G1), a idade variou entre 25 e 55 anos, dos quais seis eram solteiros, cinco casados e um divorciado. Quanto ao nível de escolaridade, dois apresentavam 
nível superior, quatro apresentavam ensino médio completo, dois tinham ensino fundamental completo e quatro não haviam concluído o ensino fundamental. Em relação à ocupação, esta se apresentou bastante diversificada: comerciantes, ambulantes, funcionário público, corretor de veículos, representante comercial, técnico em informática, porteiro de condomínio, motoboy. A renda individual apresentou média de $\mathrm{R} \$ 1.091,25$ e a renda média familiar correspondeu a $R \$ 3.103,33$. Nesse grupo, três participantes eram responsáveis pela renda geral da família.

Em relação aos participantes do bairro popular (G2), foram encontradas uma variação de idade entre 25 e 58 anos, sendo três solteiros, dois casados e sete em união estável. Oito entrevistados apresentaram ensino fundamental incompleto, um com ensino fundamental completo, dois com o ensino médio completo e um se declarou analfabeto. Para a ocupação, foram relatadas as seguintes categorias: autônomo, auxiliar de serviços gerais, aposentado, mecânico, vendedor, padeiro, vendedor ambulante, vigia, gari, auxiliar de marceneiro e ajudante de pedreiro. A renda individual média do grupo foi de $\mathrm{R} \$ 744,00$ e a renda média familiar foi de $\mathrm{R} \$ 1.097,50$. Aqui, seis homens eram responsáveis pela renda geral de suas famílias.

\section{Os sentidos de saúde e de homem}

Por meio das associações de ideias com a palavra saúde, foi recorrente uma compreensão da mesma como elemento central na vida das pessoas, como fenômeno fundamental para uma condução qualificada de suas existências:

[...] Saúde é tudo pra agente, né? o que nos permite ficar em pé e meter a bola pra frente (Hefesto, 35 anos, G1).

Ah, saúde é felicidade né? [...] Felicidade é porque a pessoa que tem saúde só vive feliz, não vive sentindo algumas dores, alguns problemas. Pra mim o 'cabra' vive feliz tando com saúde (Héracles, 54 anos, G1).

Em termos gerais, os sentidos atribuídos à saúde pelos participantes, independentemente do grupo ao qual pertenciam, estavam vinculados à sua importância enquanto algo primordial na vida para ser ter alegria, alcançar objetivos, disposição para realizar as atividades do dia-a-dia, principalmente o trabalho, ter capacidade ou nada que impeça do indivíduo trabalhar, estar bem fisicamente, livre de doenças, com os órgãos em perfeito funcionamento, como sendo a própria vida em si e, por fim, proporcionando ao sujeito sentir-se em paz ou em tranquilidade.

Pode-se considerar que tais produções discursivas refletem o imaginário social construído em torno da saúde em que concepções variadas (biológicas, sociais, culturais, psicológicas) comparecem nos repertórios lançados para significar o termo em questão, especialmente se tomarmos em conta a popularização que o conceito de saúde ganhou através da Organização Mundial de Saúde (OMS).

A diversidade desses repertórios variava, ainda, conforme o nível de instrução dos entrevistados, bem como o grau de familiaridade que demonstravam com os serviços de saúde e as experiências que com eles tiveram, de modo que, nessas duas situações, percebeu-se que os sentidos produzidos sobre a saúde partiam dos conhecimentos socializados tanto pelo saber formal quanto oriundo das relações estabelecidas com as instituições na busca de tratamento de saúde.

Nesse último caso, os sentidos produzidos por meio das práticas discursivas com os pesquisadores articulavam o tempo vivido, em que o fenômeno saúde era significado por meio das experiências acumuladas pelos homens junto aos serviços. Assim sendo, a saúde também era referida a partir da qualidade com que os serviços se expressavam quando eram demandados pelos homens. Se a experiência vivida no serviço não foi satisfatória, ou se não tinha sido dotada de resolutividade, logo se qualificava a saúde de forma negativizada:

[...] eu acho que tá muito ruim, muita... saúde. [...] principalmente nesses hospitais, a pessoa vai, não arranja nada [...] (Órion, 58 anos, G2).

Em relação ao G2, vinculado à Unidade de Saúde da Família, alguns aspectos se diferenciavam no tocante ao modo como foram encaminhadas as demandas e necessidades de saúde apresentadas pelos usuários entrevistados nesse serviço. Percebe-se uma diferença no acesso e acolhimento oferecidos, onde as queixas apareceram com menor incidência e os sentidos sobre saúde dotados de maior positividade. 
Identificamos que essa positividade tem ligação com o modelo de atenção adotado na Unidade de Saúde em questão, que tem vinculação com a Estratégia de Saúde da Família (ESF). Esta, por sua vez, visa reorientar o modelo de assistência em saúde por meio de equipes multiprofissionais nas unidades básicas e que acompanham famílias num dado setor geográfico de uma comunidade ou bairro. Presta, assim, uma atenção mais próxima do cotidiano da população em termos de promoção e prevenção em saúde (Brasil, 2012).

Em muitas falas, esteve também evidente o forte vínculo entre saúde e a responsabilidade de provedor da família. Perder a saúde, para os homens entrevistados, estava estritamente relacionado com o fato de prejudicar toda a família, uma vez que comprometeria a função do homem no sustento do lar tendo em vista o seu lugar historicamente atribuído enquanto sujeito do trabalho e guardião do ambiente doméstico:

Se você não tiver saúde você não vai conseguir produzir bem no seu emprego, não vai ter uma boa vivência em casa, muitas pessoas vão ficar... como se diz... meio presas a você, né? [...] Ainda mais no meu caso, eu que sou o cabeça da família, se eu adoecer, eu acho que tudo gira em torno de mim, entendeu? Adoecer, eu sou um representante, não tem salário, as contas atrasam e etc. e etc. (Dionísio, 33 anos, G2).

As falas expressam, ainda, a preocupação com o estado de saúde no sentido de que sem ela não é possível o indivíduo prosseguir no trabalho, de maneira a se sentir improdutivo:

É poder trabalhar, sem doença. [...] Quando eu trabalhava no serrado eu era tipo um bicho, pegava peso direto. Aí, depois que eu levei essa queda de bicicleta, não sou mais pra nada, assim, de trabalhar. Acabou-se minha saúde e minha liberdade. E o meu trabalho, né? Eu não consigo mais trabalhar (Teseu, 32 anos, G1).

Sem saúde você não é nada, você não pode trabalhar [...] (Eros, 53 anos, G2).

Os sentidos atribuídos à saúde, como a capacidade ou disposição para o trabalho, embora tratados nas falas dos homens dos dois grupos, notou-se presente, sobretudo, nos participantes do grupo do bairro popular (G2), em que quase o dobro dos entrevistados em relação aos do bairro de classe média (G1) fizeram tal associação. É pertinente lembrar que metade do grupo de homens do bairro popular informou ser responsável por toda a renda familiar. Scott (2010) comenta que muitos estudos já enfatizaram o fato de que os homens, quando chefes de domicílio, identificam-se com o papel de provedor e sua família subordinada, tornando-se uma "instituição hierárquica" (p. 88).

Percebemos, neste caso, os atravessamentos dos papéis de gênero no que se refere ao discurso produzido pelos sujeitos acerca da saúde. Essa relação ficou mais expressiva, sobretudo, nas falas em que os entrevistados puderam discorrer sobre os sentidos de ser homem. Quando indagados sobre o tema, percebeu-se certo estranhamento por parte de alguns participantes. Talvez por parecer um questionamento incomum frente a um conceito que remete a um lugar já posto, sustentado enquanto natural e, por vezes, incontestável:

Ser homem? [...] Tem que responder é? [...] Ser homem é ser homem. Pronto. É homem. Ou é ou não é (Agamenon, 45 anos, G2).

Atribuiu-se ao ser homem consideravelmente qualidades morais, como agir de maneira correta, respeitável, com dignidade e caráter, ter atitude, ser um bom cidadão e ser bom pai, educar os filhos, buscar ser o melhor em todos os aspectos, saber dialogar com a família, cumprir seus deveres, "andar sempre na linha”, como exemplificado na fala:

Ser homem pra mim é honrar minha... como é que se diz... ser homem! (Exclama com ênfase) Eu nasci homem pra ser homem mesmo. [...] É ter palavra, ser sincero. Isso é que é ser homem (Héracles, 54 anos, G1).

Os sentidos de ser homem ligados a valores morais também foi marcada no estudo de Gomes et al. (2007) junto a homens, na cidade do Rio de Janeiro. Os autores sugerem que tal apelo tem por finalidade exercer uma forma de controle sobre a sexualidade masculina entendida, muitas vezes, como desregrada e desobediente, daí a necessidade de uma moralidade que a insira numa ordem social.

As diferenças biológicas ou físicas enquanto condições para o ser homem foram citadas em 
poucas falas, de maneira sutil e às vezes, contraditória: como aquele que tem natureza diferente da mulher, aquele que nasce e aceita a forma como homem - ressaltando-se que um dos entrevistados traz dois aspectos diferentes em sua fala - ao dizer que o homem já nasce homem, a seguir destaca que assim como a mulher se torna mulher, citando a célebre afirmação de Simone de Beauvoir, alega que o homem também se constitui enquanto tal:

[...] apesar de ter o... todo o organismo de homem, o corpo também do social que se dá, entendeu? O padrão social que se tem [...] (Perseu, 25 anos, G1).

Esse participante, um dos poucos a cursar o ensino superior, evidenciou um entendimento do ser homem enquanto aprendizado de comportamentos e padrões estabelecidos socialmente. Vê-se, portanto, na posição citada acima, dois aspectos distintos compondo a definição do ser homem: aquele que já nasce enquanto tal, com seus condicionantes físicos ou biológicos e aquele que se constitui homem ao reproduzir determinados padrões de conduta. Um desses comportamentos esperados, inclusive, refere-se à heterossexualidade, como citado por um participante:

[...] o bom homem gosta da mulher, néisso? tem que ter uma mulher [...] (Urano, 39 anos, G2)

Tais repertórios utilizados para dar sentido ao ser homem apresentam uma forte ligação com o que Mota (2008) denomina de um modelo heterocêntrico de sociedade em que se valoriza, sob a baliza de tal modelo, a parentalidade e a conjugalidade. A dominância desses fatores tem uma marca histórica muito forte em nossa sociedade ocidental que tem sido incorporada em nosso cotidiano de modo naturalizada.

Utilizou-se, ainda, atributos como o "sexo forte", o que é livre, que tem mais agilidade, força física, disposição para trabalhar e que pensa mais rápido que a mulher, aquele que constitui uma família, que busca se aperfeiçoar no seu trabalho, que aceita serviços que exigem força braçal e o chefe de família ou responsável pelo sustento da casa este, na verdade, sujeito comprometido de cumprir seus deveres e responsabilidades, enquanto figura incumbida pela providência do lar. Essa última ideia foi bastante recorrente na fala dos entrevistados, de maneira que oito participantes de cada grupo discorreram acerca de tal assunto quando se referiram ao sentido de ser homem:

Significa, assim, é... ter caráter, ter suas responsabilidades [...] um exemplo, assim... a nossa família, né, então, nós temos responsabilidades em manter a nossa família, é... digna, né? em todos os aspectos, né? mais ou menos assim [...] (Hefesto, 35 anos, G1).

[...] o homem tem prioridade mais que a mulher, né? Assim, na palavra, na... é... no mandar em casa, as responsabilidades. [...] se não tem um homem, não tem pai pra mandar, é... pra exigir alguma coisa, a coisa fica mesmo bagunçada, né? (Alfeu, 48 anos, G2).

Ressaltamos que, embora nove dos 24 entrevistados respondessem pela renda geral da família, dezesseis construíram sentidos de homem a partir da ótica de responsável e provedor da família e do lar. Mesmo que não o fossem totalmente, mas assim se posicionavam discursivamente. Embora reconhecessem a presença feminina na força produtiva, mas a identificavam como facultativa, diferentemente de si, que significava um imperativo moral.

Foi perceptível, ainda, a contradição de ideias ocorridas nas entrevistas quando alguns entrevistados se posicionavam acerca dessa relação homem/trabalho ou do papel do homem na composição familiar, como exemplificado na fala abaixo:

Entrevistado:[...] se for preciso ela trabalhar, aí vai, tá no direito dela, né? se ela quiser ir. Do mesmo jeito, tá do homem. Se ele não quiser trabalhar também, também não trabalha, né? Tá no direito dele (Odisseu, 25 anos, G1).

Entrevistador: mas você disse que o homem... ser homem significa trabalhar...

Entrevistado: É isso que eu digo, é... a responsabilidade do homem é ele trabalhar. Pra ele ser homem ele tem que trabalhar, porque o homem que é homem, ele não trabalha, ele não é homem (Odisseu, 25 anos, G1). 
Tal contradição pode ser tomada como um reflexo do convívio atual de discursos sobre a família: um mais tradicional em que centraliza o homem como provedor do lar e um que questiona esse estatuto e ganhou força nas últimas décadas com o avanço dos movimentos feministas e dos estudos de gênero.

Em outros termos, a presença desses discursos pode nos informar da historicidade dos sujeitos que emergem como efeito desses mesmos discursos. Assim, a experiência da masculinidade não nos informa de um modo essencial e universal com o qual homens se alinham, mas de recortes históricos em que convenções são produzidas na busca de interpelar os sujeitos. A esse respeito, Gergen (2009, p. 303), um dos representantes do Construcionismo social destaca que "os termos com os quais entendemos o mundo são artefatos sociais, produtos historicamente situados de intercâmbios entre as pessoas", ponto que nos leva à possibilidade de situar a produção sentidos de modo a incorporar essa historicidade, afastando, assim, uma naturalização desses conhecimentos elaborados pelos homens sobre sua saúde.

Em suas práticas discursivas emergem repertórios que tanto nos informam do tempo longo das ideias e conteúdos cristalizados em nossa cultura, bem como do tempo curto em que outros conteúdos começam a fazer parte da socialização dos sujeitos, gerando uma polissemia em torno do tema em questão. Tal conflito de papéis trouxe a contradição de discursos relativos não somente ao dever do homem trabalhar, mas ainda ao forte discurso hegemônico que encerra o trabalho enquanto condição para o ser homem - há até um reconhecimento de que homens e mulheres têm o mesmo direito - mas ao se referirem ao trabalho, é este fenômeno que faz do homem, homem:

[...] Ser homem na vida é... como a gente somos, pronto... trabalhador. [...] Agente somos homem para fazer nossas atividades, né isso? No trabalho, dia a dia, tem que ser um cara para se responder [...] não... nasceu para ser homem, pra ser um homem mesmo, para trabalhar e fazer tudo, pai de família e tudo, pronto (Urano, 39 anos, G2).

Nesse sentido, fica evidente a aproximação entre um modelo de homem atrelado à atividade produtiva. Sobre esse aspecto, Barker (2010) assinala que o trabalho se destaca como um importante amálgama na construção da identidade social de homens adultos que, em várias realidades sociais, são convocados a tornar sinônimos masculinidade e possuir trabalho.

Além de tais competências, ser homem, como colocado por cinco entrevistados do G2, seria ter "energia" ou disposição para trabalhar em qualquer serviço. Nota-se um destaque para as atividades laborais mormente consideradas "pesadas": trabalhos que exigem grande desempenho físico ou força braçal. Podemos relacionar o realce em "atividades pesadas" por integrantes do grupo com seu nível de escolarização, mais baixo que o G1, na medida em que sabemos como a formação escolar é um fator de distinção social e de oportunidade para determinados tipos de trabalho. As atividades que demandam "força física" guardam, historicamente, um lugar de desvalorização social e reservado a camadas mais pobres e não letradas da nossa sociedade:

[...] o homem ele trabalha em todo serviço geral e a mulher já é diferente, né? A mulher se ela só pode trabalhar se for um emprego, que seja um emprego... doméstico pra ela ou um emprego de... escritório, essas coisas. E o homem não. O homem é... no meu pensamento, ele trabalha em todo serviço geral que achar pra ele, né?É as grande 'pedreira', é tudo (Órion, 58 anos, G2).

[...] o homem encara mais serviço mais... por exemplo, pesado, que a mulher não tem, não pode [...] e também vai de, de... depende de você. Você não tendo estudo, você também não... você vai batalhar pra estudo, né? Como no meu caso, né? Eu não tive estudo, não tive tempo pra estudar [...] (Édipo, 25 anos, G2).

A posição de responsabilidade e providência do lar foi notada, sobretudo, nos próprios motivos pelos quais os homens se dirigiam à UBS: no caso do serviço de saúde localizado no bairro de classe média, dos 12 homens abordados para entrevista, seis estavam acompanhando o atendimento de algum membro da família (filhos ou esposa).

Esse lugar do homem enquanto responsável pela família, portanto, não se situou somente no campo financeiro como mostrou nossa experiência de campo, mas também enquanto responsável pelo cuidado dos seus integrantes. Assim, identificamos, no contexto pesquisado, que o homem também compartilhava com a mulher o cuidado familiar, de forma que mesmo estando bastante presente nos seus repertórios discur- 
sivos a falta de tempo para procurar os serviços de saúde devido ao trabalho, percebeu-se que, paradoxalmente, conseguiram dispor de tempo para se deslocar até a unidade de saúde em busca de cuidados para os filhos ou esposa. Isso nos faz pensar acerca do lugar do cuidado que o homem dispõe para sua saúde estar sempre em última instância, pois em primeiro lugar está a responsabilidade de suprir as necessidades do lar.

Por outro lado, tal aspecto insere os homens numa atividade tida até então como feminina: o cuidado com os membros da família (Barker, 2010). Acompanhar a educação e a saúde dos filhos constituiu-se, por muito tempo, uma responsabilidade das mulheres e que passa, na atualidade, a ser compartilhada com os homens.

\section{O cuidado com a saúde}

A adoção de formas de cuidado com a saúde pode ser tomada como um importante indício de como homens e mulheres são tomados por discursos médicos e práticas sociais generificadas. Assim, por meio das práticas discursiva dos participantes do presente estudo, podemos refletir como os termos gênero e saúde se aproximam e são balizadores de tais formas de cuidado.

Os participantes do G2 foram unânimes em responder que os homens são bastante displicentes em relação ao cuidado de sua saúde se comparados com as mulheres. Metade dos participantes do G1 também se posicionou dessa forma, quatro alegaram que o homem e a mulher dispendem atenção semelhante e dois disseram que os homens cuidam mais de sua saúde que as mulheres.

$\mathrm{O}$ cuidado com a saúde articulado à procura pelos serviços foi tratado pela maior parte dos entrevistados (seja falando dos homens de maneira geral, seja citando o próprio exemplo) como sendo o último recurso buscado quando já se está bastante debilitado. Tal colocação foi proferida por 11 homens do G2 e apontada por metades dos sujeitos do G1, como exemplificada nas falas:

[...] É só quando tá nas últimas mesmo. [...] Enquanto ele puder tá segurando, ele tá segurando. Eu acho que é todo homem. Eu acho não é só eu não (Alfeu, 48 anos, G2).

[...] Eu só vou mesmo quando eu tô arriado mesmo de alguma coisa [...] (Hermes, 28 anos, G1).
Ao investigar a utilização de serviços de saúde por 1.095 homens em cinco estados brasileiros, Nascimento e Gianordoli-Nascimento (2011) encontraram uma frequência de 29,04\% dos participantes que informaram nunca ter procurado um consultório e 45,23\% nunca ter procurado uma unidade de saúde.

De acordo com os participantes, os motivos por não procurarem os serviços teriam relação com o fato de os homens serem mais displicentes no cuidado com a saúde, medo de descobrir que algo não vai bem, constrangimento em expor o corpo para uma profissional, a mulher ser mais carente de cuidados ou apresentar mais enfermidades, o homem ser mais preocupado com o trabalho em detrimento da saúde, bem como já nascer "relaxado" e "grosseiro". Alguns alegaram que as mulheres frequentam mais os serviços de saúde porque são mais frágeis, carentes de mais cuidado ou mesmo porque apresentam mais problemas de saúde em relação aos homens:

Eu acho que a mulher quando ela já nasce mulher, ela já nasce... o homem é um bicho grosseiro, vamos dizer assim, é mais... mulher é mais delicada [...] (Dionísio, 33 anos, G2).

A mulher cuida mais porque ela tem... é... as que eu conheci, né? tiveram vários problemas, mais que os homens (Apolo, 32 anos, G1).

Nota-se, portanto, que por trás desse discurso de fragilidade feminina está a crença da invulnerabilidade masculina ou de que os homens são menos suscetíveis a contrair enfermidades que as mulheres. Santos, Almeida, Maravilha e Oliveira (2011) pontuam que a prática higienista adotada pelas políticas de Estado, ao dar visibilidade às mulheres e produzir sua medicalização, acabou por invisibilizar os homens. Para as autoras, tal fenômeno ancorou-se num estereótipo de gênero a partir do qual as doenças, ao revelarem sinal de fragilidade, não seriam inerentes à condição biológica masculina. Desse modo, torna-se delicado para homens que se subjetivaram a partir de tal discurso, reconhecerse demandantes de cuidados em saúde, fato que estaria colocando em questão sua própria masculinidade.

Outro aspecto que pode ter relação com essa maior vinculação das mulheres aos serviços de saúde, segundo os homens entrevistados, diz de um discurso generificado para o campo da saúde onde historicamente se associou as práticas de 
cuidado à feminilidade, criando modos de relação e repertórios distintos para os homens e as mulheres no tocante ao cuidado em saúde (Lago, \& Muller, 2010). A partir dos discursos estabelecidos socialmente sobre essa distinção, muitos homens podem se posicionar de modo a elaborar sentidos que os afastam do cuidado em saúde. Nesses termos, recriar os sentidos sobre saúde e o seu cuidado implica, também, rever os sentidos de masculinidade adotadas pelos homens.

Desse modo, consideramos que um conjunto de barreiras pode dificultar o acesso dos homens tanto aos serviços de saúde, quanto ao estabelecimento de práticas de cuidado que, por sua vez, se ressignificadas, podem conduzir à quebra de padrões ou balizas que orientam, sob o espectro da invulnerabilidade, a própria definição de masculinidade.

\section{Conclusão}

Podemos apontar, conclusivamente, que os dados encontrados na presente investigação acompanham a tendência dos estudos já realizados no campo, especialmente no aspecto de como as posições sociais de gênero conformam os sentidos que os homens investigados constroem em relação à saúde, atribuindo a essa a importância de proporcionar as condições de exercício de uma masculi-

\section{Referências}

Barker, G. (2010). Trabalho não é tudo, mas é quase tudo: homens, desemprego e justiça social em políticas públicas. In: B. Medrado, J. Lira, M. Azevedo,\& J. Brasiliano (Orgs.), Homens e masculinidades: práticas de intimidade e políticas públicas (pp. 125-137). Recife, PE: Instituto PAPAI.

Bento, B. (2006). Estudos de gênero: o universal, o relacional e o plural. In B. Bento (Org.), A reinvenção do corpo: sexualidade e gênero na experiência transexual (pp. 69-108). Rio de Janeiro, RJ: Garamond.

Brasil. Ministério da Saúde (2009). Portaria $n^{\circ}$ 1.944, de 27 de agosto de 2009. Institui no âmbito do Sistema Único de Saúde (SUS), a Política Nacional de Atenção Integral à Saúde do Homem. Brasília, DF: o autor.

Brasil. Ministério da Saúde. Portal da Saúde (2012). Programa de Saúde da Família. Recuperado de http://portal.saude.gov.br/portal/saude/cidadao/ area.cfm?id_area=149 nidade voltada para o gerenciamento e provimento do lar e da família.

O trabalho se destacou como um dispositivo importante de definição de identidade masculina, especialmente pelo seu valor moral e de manutenção do controle da família. Por outro lado, emergiram falas relativizando a centralidade do trabalho em torno da figura masculina. Identificamos, ainda, que as experiências anteriores com os serviços de saúde têm um papel importante na qualificação dos sentidos que os homens atribuem à saúde, seja dotando-a de positividade ou negatividade. Percebemos como a busca pelos serviços de saúde em nível de atenção básica é limitada, fato que segue a tendência de que os homens buscam os serviços de saúde já quando se encontra em níveis de demanda por atenção especializada (Gomes, 2008).

Por fim, entendemos que para a superação do conjunto de barreiras que impedem o acesso dos homens aos serviços de saúde - seja porque estes não estão estruturados para as especificidades de tal população, seja porque a adoção de práticas de cuidado implique em redefinir a noção de masculinidade - a PNAISH pode ter uma importante contribuição na medida em que se efetive como política de saúde, sensibilizando a toda a rede de atores e serviços envolvidos na busca por novos olhares e práticas em torno da relação gênero-saúde.

Brasil. Ministério da Saúde. Secretaria de Atenção à Saúde. (2008). Política de atenção integral á saúde do homem (princípios e diretrizes. Brasília, DF: o autor.

Carrara, S., Russo, J., \& Faro, L. (2009). A política de atenção à saúde do homem no Brasil: os paradoxos da medicalizaçãodocorpomasculino. Physis, 19(3),659-678. doi:10.1590/S0103-73312009000300006

Gergen, K. (2009). O movimento do construcionismo social na psicologia moderna. Revista Interthesis, 6(1), 299-325. doi:10.5007/1807-1384.2009v6n1p299

Gomes, R. (2008). Sexualidade masculina, gênero $e$ saúde. Rio de Janeiro, RJ: Fiocruz.

Gomes, R., Nascimento, E. F., \& Araújo, F. C. (2007). Por que os homens buscam menos os serviços de saúde do que as mulheres? As explicações de homens com baixa escolaridade e homens com ensino superior. Cadernos de Saúde Pública, 23(3), 565-574. doi:10.1590/S0102-311X2007000300015 
Granja, E., \& Medrado, B. (2009). Homens, violência de gênero e atenção integral em saúde. Psicologia \& Sociedade; 21(1), 25-34. doi:10.1590/S0102-71822009000100004

Lago, M. C. S., \& Muller, R. C. F. (2010). O sujeito universal do cuidado no SUS: gênero, corpo e cuidado com a saúde nas falas de profissionais e usuários do hospital universitário - Florianópolis, Santa Catarina. In M. N. Strey, C. Nogueira, \& M. R. Azambuja (Orgs), Gênero e saúde: diálogos ibero-brasileiros (pp. 279-302). Porto Alegre, RS: EdiPUCRS.

Medrado, B., \& Lira, J. (2008). Por uma matriz feminista de gênero para os estudos sobre homens e masculinidades. Revista Estudos Feministas, 16(3), 809-840. doi:10.1590/S0104-026X2008000300005

Mota, M. P. (2008). As diferenças e os "diferentes" na construção da cidadania gay: dilemas para o debate sobre os novos sujeitos de direito. Bagoas, 2(2), 191-210. Recuperado de http://ufrn.emnuvens.com.br/bagoas/article/view/2274

Nascimento, A. R. F., \& Gianordoli-Nascimento, I. F. (2011). A utilização dos serviços de saúde pelos homens: frequências e motivos. In Z. Trindade, M. C. S. Menandro, \& C. R. R. Nascimento (Orgs.), Masculinidades e práticas de saúde (pp. 171-186). Vitória, ES: GM.

Rio Grande do Norte. Secretaria de Estado da Saúde Pública (2012). Atenção à saúde com foco na vigilância epidemiológica: relatório de situação: Rio Grande do Norte 2011. Natal, RN: o autor.

Santos, M. F. S., Almeida, A. M. O., Maravilha, L. M. M., \& Oliveira, E. C. (2011). Cuidar da saúde é coisa de homem? In Z. Trindade, M. C. S. Menandro, \& C. R. R. Nascimento (Orgs.), Masculinidades e práticas de saúde (pp. 149-170). Vitória: GM.

Scott, J. (1995). Gênero: uma categoria útil de análise histórica. Revista Educação e Realidade, 20(2), 71-99.

Scott, R. P. (2010). Homens, domesticidade e políticas públicas na saúde reprodutiva. In B. Medrado, J. Lira, M. Azevedo, \& J. Brasiliano (Orgs.), Homens e masculinidades: práticas de intimidade e políticas públicas (pp. 79-93). Recife: Instituto PAPAI.

Spink, M. J. (2000). Práticas discursivas e produção de sentido no cotidiano: aproximações metodológicas. São Paulo, SP: Cortez.

Spink, M. J., \& Frezza, R. M. (2000). Práticas discursivas e produção de sentidos: a perspectiva da psicologia social. In M. J. Spink (Org.), Práticas discursivas e produção de sentido no cotidiano: aproximações metodológicas (pp. 17-40). São Paulo, SP: Cortez.

Spink, M. J., \& Lima, B. (2000). Rigor e visibilidade: a explicitação dos passos da interpretação. In M. J. Spink (Org.), Práticas discursivas e produção de sentido no cotidiano: aproximações metodológicas (pp. 93-122). São Paulo, SP: Cortez.

Spink, M. J., \& Medrado, B. (2000). Produção de sentido no cotidiano: uma abordagem teórico-metodológica para a análise das práticas discursivas. In M. J. Spink (Org.), Práticas discursivas e produção de sentido no cotidiano: aproximações metodológicas (pp. 41-61). São Paulo, SP: Cortez.

Jáder Ferreira Leite

Professor adjunto do Departamento de Psicologia da UFRN.

E-mail: jaderfleite@gmail.com

\section{Magda Dimenstein}

Professora Titular do Departamento de Psicologia da UFRN.

E-mail: mgdimenstein@gmail.com

\section{Rafaele Paiva}

Graduada em Psicologia pela UFRN.

E-mail: rafinhaanjos07@hotmail.com

\section{Lúcia Carvalho}

Mestre em Psicologia pela UFRN. Psicóloga da Secretaria Municipal de Saúde de Natal/RN.

E-mail: lucifatima@uol.com.br

Ana Karenina de Melo Arraes Amorim

Professora adjunta do Departamento de Psicologia da UFRN.

E-mail: akarraes@gmail.com

\section{Aparecida França}

Doutora em Psicologia pela UFRN, psicóloga da Secretaria Estadual de Saúde/RN e docente do curso de Psicologia da Universidade Potiguar.

E-mail: cidafrance@gmail.com

Endereço para envio de correspondência:

Alameda das Mansões, 218 - Torre São Paulo, apto. 802 - Bairro Candelária. Natal/RN. CEP: 59064-740 
Recebido: $12 / 08 / 2013$

Reformulado: 14/04/2015

Aprovado:31/03/2016

Received:08/12/2013

Reformulated: 14/04/2015

Approved: 03/31/2016

Recibido: $12 / 08 / 2013$

Reformulado: $14 / 04 / 2015$

Aceptado: 31/03/2016

Como citar: Leite, J. F, Dimenstein, M., Paiva, R., Carvalho, L., Amorim, A. K. M. A., França, A. (2016). Sentidos da saúde numa perspectiva de gênero: um estudo com homens da cidade de Natal/RN. Psicologia: Ciênciae Profissão, 36(2): 341-353. doi:10.1590/1982-3703001812013

How to cite: Leite, J. F., Dimenstein, M., Paiva, R., Carvalho, L., Amorim, A. K. M. A., França, A. (2016). Health senses a gender perspective: a study of men in the city of Natal/RN. Psicologia: Ciência e Profissão, 36(2): 341-353. doi:10.1590/1982-3703001812013

Cómo citar: Leite, J. F., Dimenstein, M., Paiva, R., Carvalho, L., Amorim, A. K. M. A., França, A. (2016). La salud detecta una perspectiva de género: un estudio de hombres en la ciudad de Natal/RN. Psicologia: Ciência e Profissão, 36(2): 341-353. doi:10.1590/1982-3703001812013 